\title{
Incidence of Phytophthora Blight and Verticillium Wilt Within Chile Pepper Fields in New Mexico
}

\author{
S. Sanogo and J. Carpenter, Department of Entomology, Plant Pathology, and Weed Science, New Mexico State \\ University, Las Cruces 88003-0003
}

\begin{abstract}
Sanogo, S., and Carpenter, J. 2006. Incidence of Phytophthora blight and Verticillium wilt within chile pepper fields in New Mexico. Plant Dis. 90:291-296.

Statewide surveys of commercial chile pepper (Capsicum annuиm) fields were conducted in New Mexico from 2002 to 2004 to gain information on the incidence of diseases with wilt symptoms and their causative agents. Fifty-nine fields were surveyed during the course of this 3year study when chile pepper plants were at growth stages from green fruit to beginning red fruit. All fields were affected by diseases with wilt symptoms. The proportion of total field area exhibiting symptoms of wilt spanned from less than $1 \%$ to over $80 \%$. Field diagnostics along with laboratory assays of wilted plants revealed that the wilting was caused by Phytophthora capsici and Verticillium dahliae. The two pathogens were both found in $80 \%$ of the fields, and occurred together in some wilted plants in $12 \%$ of the fields. Average incidence of plant infection (number of plants infected with $P$. capsici or $V$. dahliae out of 5 to 25 wilted plants sampled) varied from approximately 40 to $90 \%$ for $P$. capsici, and from 18 to $65 \%$ for $V$. dahliae. Incidence of plant infection by $P$. capsici was approximately $40 \%$ less in fields with drip irrigation than in fields with furrow irrigation. In contrast, incidence of plant infection by $V$. dahliae was approximately $32 \%$ greater under drip irrigation than under furrow irrigation. In pathogenicity tests, isolates of $P$. capsici and $V$. dahliae caused symptoms in inoculated chile pepper identical to those in field-grown chile pepper plants. Results indicate that diseases with wilt symptoms are well established in chile pepper production fields, with $P$. capsici and $V$. dahliae posing the most serious challenge to chile pepper producers in New Mexico.
\end{abstract}

Additional keywords: root rot, vascular discoloration

Chile pepper (Capsicum annuum L.) is a vital agricultural commodity in the southwestern United States. The fruit of chile pepper is harvested as either green or dried red. Whereas dried red fruit is harvested at one time during the growing season, fresh green fruit may be harvested several times prior to the fruit turning red. Chile pepper harvested as fresh green or dried red is used for fresh market and processing. New Mexico is the leading state in production, and accounted for approximately $55 \%$ of the value of U.S. chile pepper production in 2003 (2). Other states producing chile pepper include Arizona, California, and Texas.

Producers of chile pepper are confronted with several constraints including diseases and pests. A self-report survey administered to chile pepper producers indicated that diseases with wilt symptoms are the most frequently encountered problem (30)

Corresponding author: S. Sanogo

E-mail: ssanogo@nmsu.edu

This work was supported by New Mexico Agricultural Experiment Station and New Mexico Chile Commission.

Accepted for publication 30 September 2005.

DOI: 10.1094/PD-90-0291

(C) 2006 The American Phytopathological Society in New Mexico. Diseases with wilt symptoms have been studied at various times in New Mexico since the beginning of the twentieth century $(8,12,17,18)$. In 1919 , Leonian described a disease with wilt symptoms, Fusarium wilt, and identified the putative agent as Fusarium annuum (17). The only other etiological work supporting the association of $F$. annuum with chile pepper wilt was done by Crawford in 1934 (8). Since then, there has been no further report of the occurrence of Fusarium wilt in New Mexico. F. annuum is apparently synonymous with $F$. oxysporum (11), and in 1989 a new forma specialis of F. oxysporum was proposed because it was shown to be pathogenic and inciting vascular wilt only in pepper in Louisiana (27). The proposal to erect this new forma specialis has yet to be approved officially. The occurrence of $F$. oxysporum causing vascular wilt in New Mexico remains to be documented and confirmed.

In 1922, 3 years after his report on Fusarium wilt, Leonian (18) described another disease of chile pepper characterized by a blight of stem and fruit caused by Phytophthora capsici, a new species of Phytophthora. Others reported that Leonian incorrectly ascribed chile pepper wilt to $F$. annuum in his 1919 study (20). But Leonian (18), in reporting on $P$. capsici, did not make any recantation of his earlier work on $F$. annuum (17) and clearly described the new disease more in terms of stem and fruit blight than in terms of plant wilt. The new disease caused by $P$. capsici was later referred to as chile wilt in various research and extension literature, due to the wilting symptoms displayed in affected plants $(8,12,29)$. Currently, the accepted common name for the disease caused by $P$. capsici is Phytophthora blight $(25,26)$.

Although it is not known when it was first recorded in New Mexico, wilt symptoms have also been ascribed to Verticillium dahliae and Verticillium albo-atrum. In a study on cultural type of Verticillium in New Mexico, Smith (31) used Verticillium isolates recovered from chile pepper. $V$. dahliae and V. albo-atrum are two soilborne fungal pathogens that cause Verticillium wilt in a broad host range (14).

A review of past research work on diseases with wilt symptoms in chile pepper in the state of New Mexico reveals that $P$. capsici and $V$. dahliae have been the focus of that work $(5,7,13,23,29,31,34)$, which indicates that the two organisms are perhaps the only pathogens associated with these diseases. There is an undocumented consensus that Phytophthora blight caused by Phytophthora capsici is the most prevalent disease problem in chile pepper production fields in New Mexico. However, there have been no systematic field studies to appraise the distribution, etiology, and incidence of wilt symptoms in production fields within the state. Such studies, in the form of disease surveys, would provide information on the geographic distribution and seriousness of wilt symptoms and their causative agents. Information emanating from such studies should enable producers deciding on rotational crops and cultivars to prevent or reduce the dire effects of wilt-causing pathogens. During the first year of this study, three weed species were identified as new hosts for $V$. dahliae, and isolates of this fungus recovered from those weeds were pathogenic to chile pepper (28). This finding brought new information to producers and is one reason for undertaking field disease surveys.

The objective of this study was to survey commercial production fields for incidence and causal agents of the wilt symptom in chile pepper in New Mexico.

\section{MATERIALS AND METHODS}

Surveys of wilt symptoms and field diagnostics. In the growing seasons of 
2002, 2003, and 2004, fields of chile pepper were surveyed in several counties in north-central, southwestern, and southeastern New Mexico (Fig. 1). Over the 3-year period, 59 different fields were surveyed with 5,12 , and 42 fields in north-central, southeastern, and southwestern parts, respectively. Within the state of New Mexico, cultivation of chile pepper is primarily concentrated in the four counties surveyed in the southwestern region, which accounted for approximately $93 \%$ of production in 2003 (1). In the same year, the three counties surveyed in the southeastern region produced about $5 \%$ of the chile pepper harvested, and the remaining $2 \%$ of the production was contributed by several counties in central and northern areas of the state (1). Chile pepper plants were at growth stages from green fruit to beginning red fruit. Plant samples (from 5 to 25 wilted plants) were arbitrarily selected and uprooted at 5 to 10 spots in each field. Wilted plants were found by walking along W-patterns through the middle of small fields with area less than 2 ha or by driving around larger fields with area $>2$ ha. Field patterns of wilted plants were observed and recorded. Wilted plants were examined for root rot, lesions on aboveground plant parts, defoliation, and vascular necrosis in longitudinal sections of taproots or stems. Based on the literature of diseases with wilt symptoms on pepper $(6,14,19,22,25)$, symptoms observed were ascribed to specific pathogens and confirmed by isolations in the laboratory as described below. Absence of root rot accompanied by vascular necrosis in root or stem was used as an indicator of infection by $V$. dahliae. Infection by $P$. capsici, or organisms other than $V$. dahliae, was gauged by the presence of root rot and root sloughing with or without lower stem lesions. Plant infection by both pathogens was determined based on the presence of root rot and root sloughing, and vascular necrosis in root or stem. For each field surveyed, the proportion of total field area exhibiting wilt symptoms was estimated and recorded. This is an arbitrary visual method which was used to provide an estimate of wilt coverage in each field. For each set of plants sampled, incidence of wilt symptoms caused by $P$. capsici was defined as the percentage of plants with root rot. Similarly, the incidence of wilt symptoms caused by $V$. dahliae was determined as the percentage of plants displaying vascular necrosis in root or stem. The incidence of wilt symptoms caused by both pathogens was defined as the percentage of plants with root rot and root sloughing, and vascular necrosis in stem. Average incidence was computed for each field using Statistix 8 (Analytical Software, Tallahassee, FL). Except for the type of irrigation used, no other information (e.g., cultivar planted, fertilization, rotation, and yield) was collected in each field owing to difficulties in contacting growers and gathering this information from them.

Isolations from wilted plants. To confirm field diagnostics, three plants with root rot and three plants with vascular necrosis were taken from each field visited and further processed in the laboratory. From each plant, four 1-cm segments were cut from the base of each stem and upper part of the taproot. Thus, there were 12 stem segments and 12 root segments sampled. Root and stem parts were washed free of soil, surface-disinfested for $2 \mathrm{~min}$ in $0.5 \%$ sodium hypochlorite, rinsed in sterile distilled water, and plated onto water agar medium in 9-cm-diameter petri

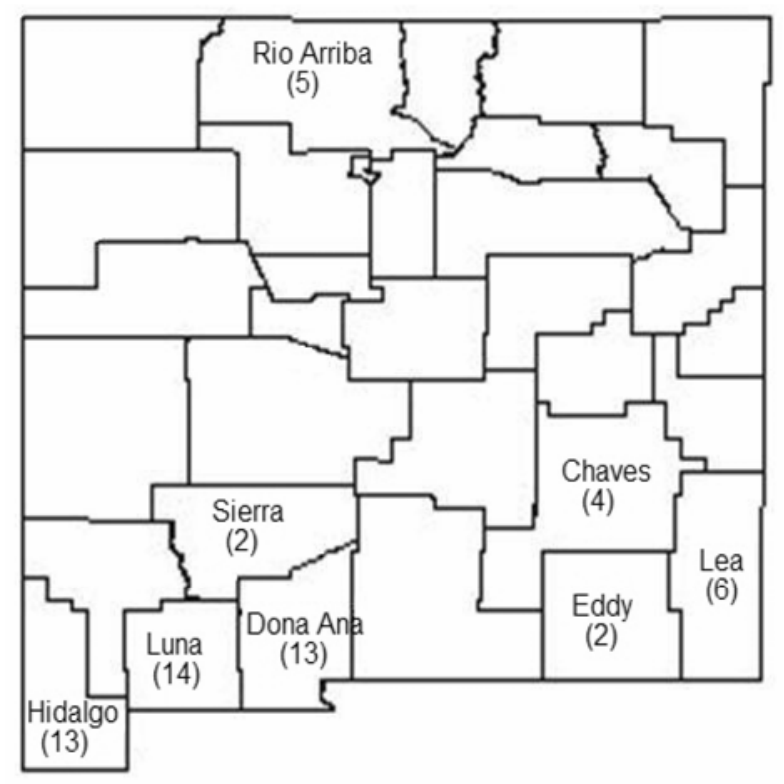

Fig. 1. Geographic location of counties in which commercial chile pepper fields were surveyed for wilt symptoms in New Mexico from 2002 to 2004. Values within parentheses below county's name represent the number of fields surveyed in each county.

plates. Mycelial colonies emerging from the plated segments were transferred to either potato dextrose agar, prune juice agar, Czapek-Dox agar, or $10 \%$ V8 agar medium in 9 -cm-diameter petri plates for identification based on morphological characteristics and microscopic observations $(10,32)$. The number of segments from which $V$. dahliae and $P$. capsici were recovered was recorded and the percentage of isolation (frequency) of these two pathogens was computed. The percentage of recovery of mycelial colonies other than those from $V$. dahliae and $P$. capsici was also computed. Average frequency of isolation and standard error of the mean frequency were calculated for each field using Statistix 8 (Analytical Software).

Pathogenicity studies. The only organism isolated from stem segments was $V$. dahliae, and the organism isolated from root segments with the highest frequencies was $P$. capsici. Therefore, pathogenicity tests were conducted only for isolates of these organisms. The ability of isolates of $V$. dahliae and P. capsici to cause wilting was tested in the greenhouse on the chile pepper cultivar NM 6-4, which is susceptible to both pathogens. Seeds of this cultivar were surfaced-disinfested in $0.025 \%$ sodium hypochlorite for $5 \mathrm{~min}$, rinsed in distilled water, and planted in six-cell (with a cell dimension of 6,4 , and $6 \mathrm{~cm}$ in length, width, and depth, respectively) plastic trays filled with sterilized TerraLite Metro Mix 360 (W. R. Grace \& Co., Memphis, TN). The planting mix was sterilized by autoclaving for $60 \mathrm{~min}$ at $121^{\circ} \mathrm{C}$ twice over two consecutive days. At the first fully expanded true leaf stage, individual seedlings were transplanted into plastic pots (with a diameter of $10 \mathrm{~cm}$ on top and $7.5 \mathrm{~cm}$ on bottom, and a depth of 9 $\mathrm{cm}$ ) filled with sterilized Terra-Lite Metro Mix 360. Seedlings were then fertilized by adding to each pot $150 \mathrm{ml}$ of 20-20-20 (N$\mathrm{P}_{2} \mathrm{O}_{5}-\mathrm{K}_{2} \mathrm{O}$ ) fertilizer (Peters Fertilizer Products, Fogelsville, PA). When seedlings were at the six- to eight-leaf growth stage, they were inoculated by pouring $25 \mathrm{ml}$ of zoospore suspension of each $P$. capsici isolate $\left(10^{4}\right.$ zoospores per $\left.\mathrm{ml}\right)$ or $20 \mathrm{ml}$ of conidial suspension $\left(10^{6}\right.$ conidia per $\left.\mathrm{ml}\right)$ of each $V$. dahliae isolate on top of the soilless medium in each pot. Noninoculated seedlings were included as controls. The inoculum levels used were within the range of those used by others $(7,16,23)$. Plants were watered daily starting immediately after inoculation. Ten isolates each of $P$. capsici and $V$. dahliae were tested. Of these 10 isolates, two, three, and five were from north-central, southeastern, and southwestern parts of the state, respectively.

Zoospores were produced following the procedure described by Bosland and Lindsey (7). Briefly, P. capsici was grown on V8 juice agar in a 9-cm-diameter petri plate in the dark at $25^{\circ} \mathrm{C}$. After 5 days, six 
mycelial plugs (1 $\mathrm{cm}$ diameter) were cut from the V8 juice agar culture and placed in $20 \mathrm{ml}$ of sterile distilled water in a 9$\mathrm{cm}$-diameter petri plate and maintained in the dark at $25^{\circ} \mathrm{C}$ for 3 days to induce formation of sporangia. The plates were then transferred to $10^{\circ} \mathrm{C}$ for $60 \mathrm{~min}$, and returned to $25^{\circ} \mathrm{C}$ for $90 \mathrm{~min}$ to trigger the release of zoospores. The content of petri plates was passed through three layers of cheesecloth to remove agar plugs, and the number of zoospores was counted using a hemacytometer.

To produce conidia of $V$. dahliae, a $1-\mathrm{cm}$ mycelial plug of $V$. dahliae grown on water agar was added to $100 \mathrm{ml}$ of sterilized Czapek-Dox broth contained in 250-ml Erlenmeyer flasks. The flasks were placed on a rotary shaker and incubated at room temperature $\left(23\right.$ to $25^{\circ} \mathrm{C}$ ) in darkness for 7 to 10 days. Then the contents of the flask were passed through three layers of cheesecloth to separate conidia from mycelial plugs and mats. The number of conidia in the filtered suspension was estimated with a hemacytometer.

The pathogenicity test was repeated once, with eight plants per isolate per test. Plants were monitored for disease development, and tissue samples were taken from representative diseased plants (three plants per isolate) and plated onto water agar medium, as described above, to confirm the association of $P$. capsici and $V$. dahliae with the observed symptoms.

\section{RESULTS}

Surveys of wilt symptoms and field diagnostics. Over the 3 -year period of the study from 2002 to 2004, a total of 59 fields were visited. Of these 59 fields, 54 were furrow-irrigated, four were dripirrigated with no plastic mulch, and one was sprinkler-irrigated. Field patterns of wilted plants were variable. In the first type, wilted plants appeared in a rowbound pattern showing progression in the direction of irrigation water movement. In the second type, wilted plants were visible as semicircular patches associated with low-lying areas of varying sizes. In the third type, single or groups of a few wilting plants were scattered throughout the field, with no associations with low-lying areas. Some fields displayed a mixture of these types.

Symptoms encountered in wilted plants were root rot with root sloughing, lesions on aboveground plant parts including fruit, and vascular necrosis on longitudinal sections of root and stem. Lesions on aboveground plant parts, including fruit, were uniquely found in the field with sprinkler irrigation and furrow-irrigated fields with saturated soils. The proportion of total field area with wilt symptoms varied from less than 1 to $90 \%$ (with an average of $15 \%$ ). Based on field diagnostics, symptoms of plant infection by $V$. dahliae were found in $80 \%$ of the fields, whereas symp- toms of plant infection by $P$. capsici were encountered in all fields. Both pathogens were present in $80 \%$ of the fields, and symptoms of coinfection (both pathogens in the same plant) were found in $12 \%$ of the fields.

In counties surveyed in the southwestern part of the state (Doña Ana, Hidalgo, Luna, and Sierra), the proportion of total field area with wilt symptoms varied from less than 3 to $90 \%$ (with an average of $18.5 \%$ ). Symptoms of plant infection by $V$. dahliae were found in $85 \%$ of the 42 fields surveyed, and average incidence of the disease in sampled plants varied from 23 to $58 \%$ (Fig. 2). Average incidence in sampled plants of wilt caused by $P$. capsici was 40 to $83 \%$, and the disease was found in all fields. Both $P$. capsici and $V$. dahliae were found in $85 \%$ of the fields. In $20 \%$ of the fields, plants were found displaying symptoms of coinfection with $V$. dahliae and $P$. capsici, with incidence ranging from 7 to $20 \%$.

In the southeastern part of the state (Chaves, Eddy, and Lea), the proportion of total field area with wilted plants ranged from less than 3 to over $20 \%$ (with an average of 5\%). Symptoms of plant infection by $P$. capsici were encountered in all 12 fields surveyed, with average incidence in sampled plants ranging from 82 to $90 \%$ (Fig. 2). Conversely, symptoms of plant infection by $V$. dahliae were found in $58 \%$ of fields, with average incidence ranging from 18 to $50 \%$. Both $P$. capsici and $V$. dahliae were encountered in $58 \%$ of the fields. No plants were found displaying symptoms of coinfection with $V$. dahliae and $P$. capsici.

In Rio Arriba, the only county that was surveyed in the north-central part of the state, the proportion of total field area with wilted plants was generally small (less than $1 \%)$. Symptoms of plant infection by $P$. capsici were found in all five fields, with average incidence in sampled plants of $48 \%$ (Fig. 2), and a range from 20 to $100 \%$. About $80 \%$ of the fields had plants with symptoms characteristic of infection by $V$. dahliae, with average incidence of $65 \%$ with a range from 50 to $80 \%$. Both $P$. capsici and $V$. dahliae were encountered in $80 \%$ of the fields. No plants were found displaying symptoms of coinfection with $V$. dahliae and P. capsici.

Isolations from wilted plants. Isolations from wilted plants yielded $V$. dahliae,

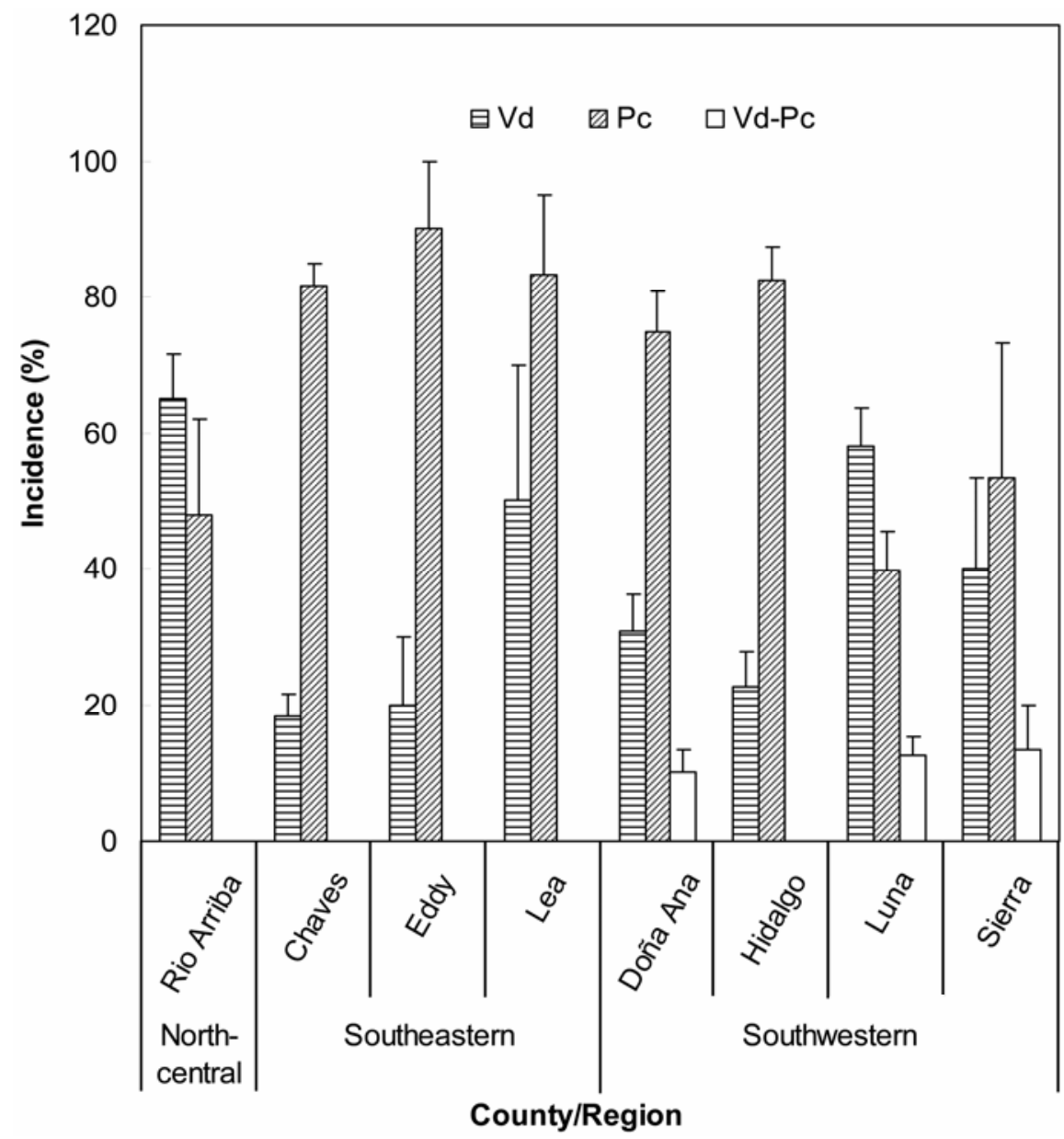

Fig. 2. Average incidence of chile pepper infection by Verticillium dahliae (Vd), Phytophthora capsici $(\mathrm{Pc})$, and both pathogens $(\mathrm{Vd}-\mathrm{Pc})$ in plants sampled from commercial chile pepper fields surveyed in southwestern, southeastern, and north-central counties in New Mexico. Bars on columns are standard error of the mean incidence in sampled plants. 
P. capsici, Rhizoctonia solani, and several other mycelial organisms consisting of species of Fusarium, Penicillium, and Aspergillus. In plants displaying root rot symptoms, $P$. capsici was the most frequently isolated across all regions, with average frequency in sampled plants ranging from 71 to $83 \%$ (Fig. 3). R. solani was also recovered from these types of plants but to a lesser extent than $P$. capsici, with average frequency in sampled plants ranging from 0 to $13 \%$. V. dahliae was the least with average frequency ranging from 0 to $4 \%$. All other mycelial organisms combined and mentioned above were isolated with average frequency in sampled plants ranging from 8 to $22 \%$. In all plants (three plants per field) displaying vascular necrosis in the stem, only $V$. dahliae was recovered. No other fungal or bacterial organisms were isolated from stems with vascular necrosis.

Irrigation type and wilt incidence. When wilt symptoms were examined with regard to irrigation type over the 3 years and across all counties, average field area with wilted plants was less than $3 \%$ in fields under drip irrigation, and approxifrequently isolated from root segments,

mately $15 \%$ in fields under furrow irrigation. Incidence of $P$. capsici in sampled plants was approximately $40 \%$ less $(P(>t)$ $=0.045)$ under drip irrigation than under furrow irrigation (Fig. 4A). Conversely, incidence of $V$. dahliae in sampled plants was about $32 \%$ greater under drip irrigation than under furrow irrigation, even though statistical significance (at $P=0.05$ ) for this difference was not indicated due to high variability $(P(>t)=0.1608)$. The frequency of isolation of both pathogens from root segments was little affected by irrigation type (Fig. 4B). Data on sprinkler irrigation were insufficient to be included in the analysis, as only one field was under this type of irrigation.

Pathogenicity studies. Wilting and vascular necrosis were observed in all 16 plants ( 8 plants per isolate in each of two trials) within 6 to 8 weeks of inoculation with each of the 10 isolates of $V$. dahliae. This pathogen was recovered from all sampled symptomatic plants. For the 16 plants ( 8 plants per isolate in each of two trials) inoculated with each of the 10 isolates of $P$. capsici, symptoms appeared within 10 to 14 days of inoculation as girdling or nongirdling stem lesions accom-

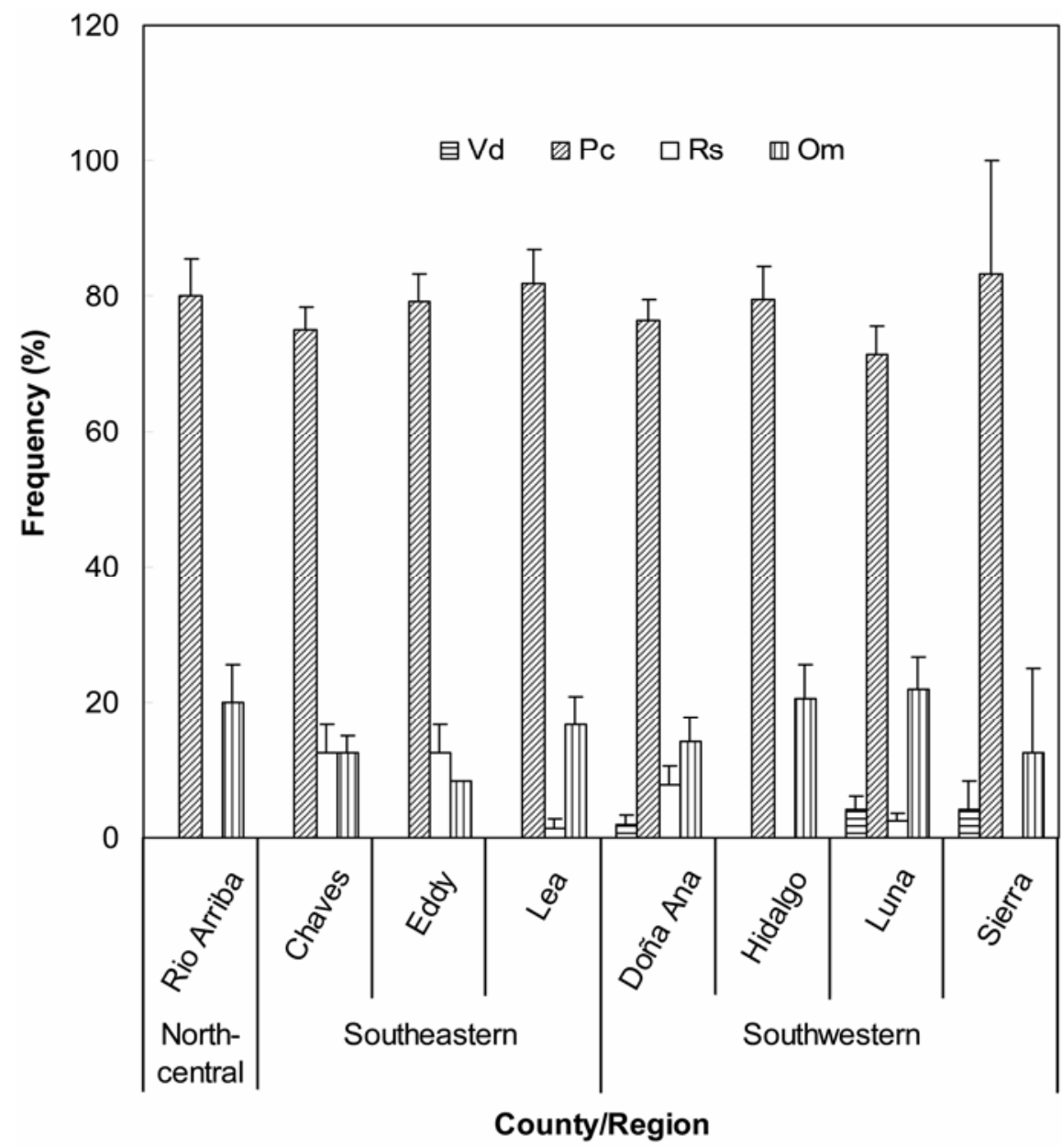

Fig. 3. Average frequency of isolation of Verticillium dahliae (Vd), Phytophthora capsici (Pc), Rhizoctonia solani (Rs), and other microorganisms $(\mathrm{Om})$ from root segments of chile pepper plants sampled from commercial fields surveyed in southwestern, southeastern, and north-central counties in New Mexico. Bars on columns are standard error of the mean frequency in sampled plants. panied by root rot and wilting. P. capsici was recovered from all sampled symptomatic plants. Although all isolates were proven to be pathogenic, virulence among these isolates was not assessed. Neither $V$. dahliae nor $P$. capsici was recovered from control plants.

\section{DISCUSSION}

This is the first known report of systematic field surveys of diseases with wilt symptoms in commercial chile pepper production fields in New Mexico. The study showed that wilt symptoms are widely distributed throughout the chile pepper growing areas, and both $P$. capsici and $V$. dahliae were associated with the wilt symptoms. $V$. dahliae was the only organism isolated from stems displaying vascular necrosis, and $P$. capsici was the organism isolated consistently with the highest frequency from root segments with rotting and sloughing symptoms. Additionally, these pathogens recovered from wilted plants were tested and demonstrated to be pathogenic on susceptible chile pepper.

Wilting in pepper, resulting from vascular or root dysfunction, may also be caused by other fungal and bacterial organisms such as F. oxysporum, Rhizoctonia solani, and Ralstonia solanacearum $(6,14,19,22)$. However, no symptoms intrinsic to these organisms were encountered, and these organisms were not isolated from any of the stem segments displaying vascular necrosis. V. dahliae was the only organism isolated from stem segments. Although $R$. solani and other mycelial organisms were isolated from root segments from the sampled plants, the frequency of their isolation was low compared with $P$. capsici, which was isolated with the highest frequency. There is no clear explicative factor for the low frequency of isolation of $V$. dahliae from root segments compared to stem segments. $P$. capsici and V. dahliae were included in the pathogenicity tests based on the frequencies of isolation from stem and root tissue along with the fact that symptoms displayed in sampled plants from surveyed fields were characteristically suggestive of infection by $P$. capsici and $V$. dahliae.

Incidence of $P$. capsici was consistently greater than that of $V$. dahliae in southeastern counties, and this trend was observed in all other counties except in Luna (southwestern part) and Rio Arriba (northcentral part). The variation in the magnitude of wilt incidence caused by $V$. dahliae and $P$. capsici across geographical regions may reflect differences in environmental conditions and cropping practices among the surveyed areas. For instance, with regard to land preparation, in southern New Mexico, the majority of producers do not laser level their fields (30), and therefore low-lying areas are commonly found in many fields. Generally, many areas of 
wilted plants within fields were characteristically low-lying areas of varying sizes in which surface water may have remained for an extended period of time following irrigation or rain events. Such areas are typified by high soil saturation and provide ideal conditions for dispersal of $P$. capsici and plant infection by this zoosporeproducing pathogen $(5,13,18)$.

In addition to land preparation, irrigation methods may explain part of the observed incidence levels. Furrow irrigation is the most practiced method in the state (30), and this present study provided supporting evidence to this fact, since approximately $92 \%$ of the fields surveyed were under furrow irrigation compared with about $7 \%$ under drip irrigation. Furrow irrigation has been shown to be conducive to increased disease level by $P$. capsici $(5,24,34)$. These findings are, in part, corroborated in this study which showed that incidence of $P$. capsici was greater under furrow irrigation than under drip irrigation. In contrast to $P$. capsici, incidence of $V$. dahliae was greater under drip irrigation than under furrow irrigation. It is unclear what factors may be contributing to the observed differential level of $V$. dahliae with regard to irrigation type.

The presence of both $P$. capsici and $V$. dahliae in the same fields is another important finding in this study and has implications for wilt management in chile pepper. The simultaneous presence of these pathogens may increase the likelihood of higher wilt incidence. Additionally, both pathogens were found in the same plants in some fields. Most cases of coinfection were found in the southwestern part of the state, a region in which chile pepper is intensively cultivated. It is possible that such an intensive system could, in part, bring about the conditions for coinfection to occur. Although the nature of this coinfection is not known, it may be of great concern if these two pathogens interact in a synergistic fashion. Under this condition, development of plant wilt may be hastened. This perspective is supported in the literature by reports of synergistic interactions among pathogenic organisms causing wilt $(9,15,21)$.

Approximately 8,20 , and $72 \%$ of the fields surveyed were located in northcentral, southeastern, and southwestern parts of the state, respectively. The extent of the survey mirrored the importance of these geographical regions in chile pepper production in the state of New Mexico with 2, 5, and $93 \%$ in central and northern, southeastern, and southwestern areas (1), respectively. The survey approach adopted was similar to those followed by others $(3,4,33,35)$. Collectively, results from this study indicate that diseases with wilt symptoms are well established in chile pepper production fields with $P$. capsici and $V$. dahliae as the major causal agents of these diseases. This information implies that chile pepper producers would need to effective management of wilt.

Yield loss is of primary concern to producers. Whereas the effect of Phytophthora blight on chile pepper yield has been assessed, the impact of Verticillium wilt on chile pepper yield has not been quantified. Xie et al. (34) conducted studies in which Phytophthora blight was shown to decrease yield of green chile pepper by $55 \%$ and target both $P$. capsici and $V$. dahliae for

combined yield of green and red chile pepper by $36 \%$. Similar results were found by Biles et al. (5), who reported that yield of green chile pepper was reduced by 48 to $55 \%$ in fields infested by $P$. capsici.

Recommendations for control of Phytophthora blight and Verticillium wilt in chile pepper include crop rotation, water management, and use of fungicides (13). Crop rotation is practiced by chile pepper producers, with alfalfa (Medicago sativa
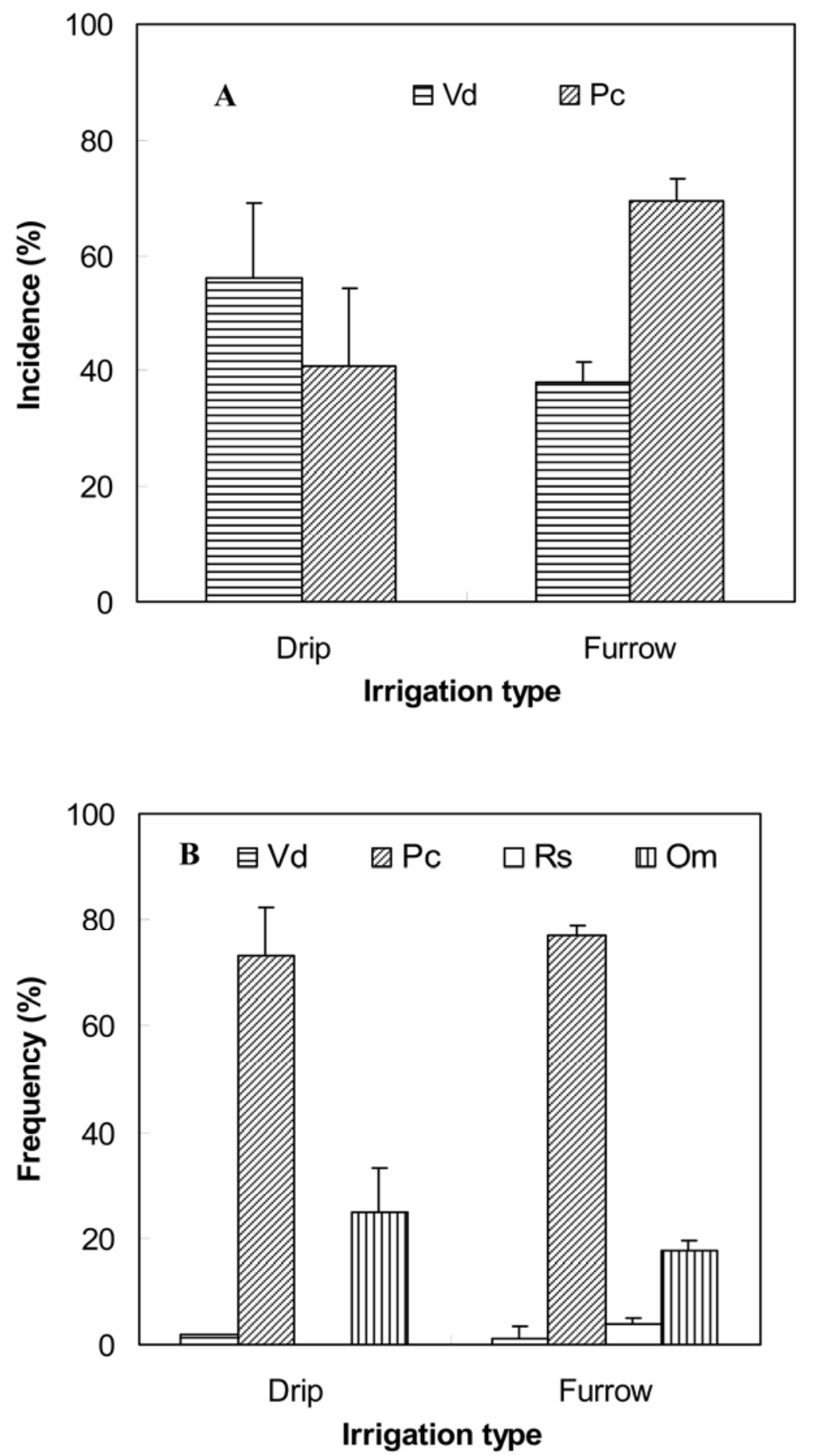

Fig. 4. A, Average incidence of chile pepper infection by Verticillium dahliae (Vd) and Phytophthora capsici $(\mathrm{Pc})$, and $\mathbf{B}$, average frequency of isolation of Verticillium dahliae $(\mathrm{Vd})$, Phytophthora capsici $(\mathrm{Pc})$, Rhizoctonia solani (Rs), and other microorganisms (Om) from root segments of chile pepper plants sampled from commercial fields under drip and furrow irrigation. Bars on columns are standard error of the mean incidence and frequency in sampled plants. 
L.) and cotton (Gossypium hirsutum L.) as the most frequently used rotational crops (30). However, the effect of crop rotation practices on Phytophthora blight and Verticillium wilt has not been examined. Chemical control is not routinely employed owing to costs and variable effectiveness. Drip irrigation and alternatefurrow irrigation are also recommended for the control of Phytophthora blight $(5,34)$. However, drip irrigation has not been widely adopted compared with furrow irrigation, perhaps due to costs associated with the implementation of drip irrigation technology (30).

Although genetic resistance has been identified in some chile pepper lines (7), currently there are no commercial chile pepper cultivars that are resistant to $P$. capsici and $V$. dahliae. The development of an affordable management scheme for Phytophthora blight and Verticillium wilt in chile pepper is needed.

\section{LITERATURE CITED}

1. Anonymous. 2004. New Mexico Chile production 2003. New Mexico Department of Agriculture, New Mexico Agricultural Statistics. Online publication.

2. Anonymous. 2004. Vegetables: Annual summary. United States Department of Agriculture, National Agricultural Statistics Service, Vg 1-2 (03). Online publication.

3. Bejarano-Alcázar, J., Blanco-López, M. A., Melero-Vara, J. M., and Jiménez-Díaz, R. M. 1996. Etiology, importance, and distribution of Verticillium wilt of cotton in southern Spain. Plant Dis. 80:1233-1238.

4. Bhat, R. G., Smith, R. F., Koike, S. T., Wu, B. M., and Subbarao, K. V. 2003. Characterization of Verticillium dahliae isolates and wilt epidemics of pepper. Plant Dis. 87:789-797.

5. Biles, C., Lindsey, D. L., and Liddell, C. M. 1992. Control of Phytophthora root rot of chile peppers by irrigation practices and fungicides. Crop Prot. 11:225-228.

6. Black, L. L. 2003. Fusarium wilt. Pages 14-15 in: Compendium of Pepper Diseases. K. L. Pernezny, P. D. Roberts, J. F. Murphy, and N. P. Goldberg, eds. American Phytopathological Society, St. Paul, MN.

7. Bosland, P. W., and Lindsey, D. L. 1991. A seedling screen for Phytophthora root rot of pepper, Capsicum annuum. Plant Dis. 75:1048-1050.

8. Crawford, R. F. 1934. The etiology and control of chile wilt, produced by Fusarium annuum. N.M. Agric. Exp. Stn. Tech. Bull., No. 223.

9. Davis, J. R., and Howard, M. N. 1976. Presence of Colletotrichum atramentarium in Idaho and relation to Verticillium wilt (Verticillium dahliae). (Abstr.) Am. Potato J. 53:397398.

10. Erwin, D. C., and Ribeiro, O. K. 1996. Phytophthora Diseases Worldwide. American Phytopathological Society, St. Paul, MN.

11. Farr, D. F., Bills, G. F., Chamuris, G. P., and Rossman, A. Y. 1989. Fungi on Plants and Plant Products in the United States. American Phytopathological Society, St. Paul, MN.

12. Garcia, F. 1933. Reduction of Chile Wilt by Cultural Methods. N.M. Agric. Exp. Stn. Tech. Bull., No. 216.

13. Goldberg, N. P. 1995. Chile Diseases. N.M. Agric. Exp. Stn., Circ. 549

14. Goldberg, N. P. 2003. Verticillium wilt. Pages 21-22 in: Compendium of Pepper Diseases. K. L. Pernezny, P. D. Roberts, J. F. Murphy, and N. P. Goldberg, eds. American Phytopathological Society, St. Paul, MN.

15. Gudmestad, N. C., Zink, R., and Otazu, V. 1977. North Dakota potato wilt survey-1977. Farm Res. 35:26-31.

16. Islam, S. Z., Babadoost, M., Lambert, K. N., Ndeme, A., and Fouly, H. M. 2005. Characterization of Phytophthora capsici isolates from processing pumpkin in Illinois. Plant Dis. 89:191-197.

17. Leonian, L. H. 1919. Fusarium Wilt of Chile Pepper. N.M. Agric. Exp. Stn. Tech. Bull. No. 121.

18. Leonian, L. H. 1922. Stem and fruit blight of chiles caused by Phytophthora capsici sp. nov. Phytopathology 12:401-408.

19. Momol, M. T., Pradhanang, P. M., and Lopes, C. A. 2003. Bacterial wilt. Pages 7-8 in: Compendium of Pepper Diseases. K. L. Pernezny, P. D. Roberts, J. F. Murphy, and N. P. Goldberg, eds. American Phytopathological Society, St. Paul, MN

20. Oelke, L. M., and Bosland, P. W. 2001. Fusarium diseases of Capsicum. Capsicum Eggplant Newsl. 20:86-89.

21. Otazu, V., Gudmestad, N. C., and Zink, R. T. 1978. The role of Colletotrichum atramentarium in the potato wilt complex in North Dakota. Plant Dis. Rep. 62:847-851.

22. Pernezny, K. L., Roberts, P. D., Murphy, J. F., and Goldberg, N. P., eds. 2003. Compendium of Pepper Diseases. American Phytopathological Society, St. Paul, MN

23. Riggs, J. L., and Graham, C. J. 1995. A screening of New Mexico Verticillium dahliae isolates for cross-infectivity to cotton and chile. Pages 218-221 in: Proceedings of the 1995 Beltwide Cotton Conference, National Cotton Council, Memphis, TN

24. Ristaino, J. B. 1991. Influence of rainfall, drip irrigation, and inoculum density on the development of Phytophthora root and crown rot epidemics and yield in bell pepper. Phytopathology 81:922-929.

25. Ristaino, J. B. 2003. Phytophthora blight Pages 17-18 in: Compendium of Pepper Diseases. K. L. Pernezny, P. D. Roberts, J. F. Murphy, and N. P. Goldberg, eds. American Phytopathological Society, St. Paul, MN

26. Ristaino, J. B., and Johnston, S. A. 1999 Ecologically based approaches to management of Phytophthora blight on bell pepper. Plant Dis. 83:1080-1089.

27. Rivelli, V. C. 1989. A wilt of pepper incited by Fusarium oxysporum f. sp. capsici f. sp. nov M.S. thesis. Louisiana State University, Baton Rouge.

28. Sanogo, S., and Clary, M. 2003. Pathogenicity on chile pepper of Vertcillium dahliae recovered from three weed hosts in New Mexico. Plant Dis. 87:450.

29. Shannon, E. 1989. Chile disease control. New Mexico State Univ. Ext. Guide H-219.

30. Skaggs, R., Decker, M., and VanLeeuwen, D. 2000. A Survey of Southern New Mexico Chile Producers: Production Practices and Problems. N.M. Agric. Exp. Stn. Tech. Bull., No. 782.

31. Smith, T. E. 1961. Cultural type of Verticillium albo-atrum in New Mexico. Plant Dis. Rep. 45:548

32. Talboys, P. W. 1960. A culture-medium aiding the identification of Verticillium albo-atrum and V. dahliae. Plant Pathol. 9:57-58.

33. Trapero-Casas, A., and Jiménez-Díaz, R. M 1985. Fungal wilt and root rot diseases of chickpea in southern Spain. Phytopathology 75:1146-1151.

34. Xie, J., Cardenas, E. S., Sammis, T. W., Wall, M. M., Lindsey, D. L., and Murray, L. W. 1999. Effects of irrigation method on chile pepper yield and Phytophthora root rot incidence. Agric. Water Manage. 42:127-142.

35. Yang, X. B., and Lundeen, P. 1997. Occurrence and distribution of soybean sudden death syndrome in Iowa. Plant Dis. 81:719-722. 